\title{
Taste Responses and Preferences for Sweet High-Fat Foods: Evidence for Opioid Involvement ${ }^{1}$
}

\author{
ADAM DREWNOWSKI, ${ }^{2}$ DEAN D. KRAHN, MARK A. DEMITRACK, \\ KAREN NAIRN AND BLAKE A. GOSNELL
}

\author{
The Program in Human Nutrition, University of Michigan School of Public Health \\ and Department of Psychiatry, University of Michigan Medical School
}

Received 5 June 1991

\begin{abstract}
DREWNOWSKI, A., D. D. KRAHN, M. A. DEMITRACK, K. NAIRN AND B. A. GOSNELL. Taste responses and preferences for sweet high-fat foods: Evidence for opioid involvement. PHYSIOL BEHAV 51(2) 371-379, 1992. - Preferences and cravings for sweet high-fat foods observed among obese and bulimic patients may involve the endogenous opioid peptide system. The opioid antagonist naloxone, opioid agonist butorphanol, and saline placebo were administered by intravenous infusion to $14 \mathrm{fe}$ male binge eaters and 12 normal-weight controls. Eight of the binge eaters were obese. During infusion, the subjects tasted 20 sugar/fat mixtures and were allowed to select and consume snack foods of varying sugar and fat content. Naloxone reduced taste preferences relative to baseline in both binge eaters and controls. Total caloric intake from snacks was significantly reduced by naloxone in binge eaters but not in controls. This reduction was most pronounced for sweet high-fat foods such as cookies or chocolate. No consistent effects on taste preferences or food intakes were observed with butorphanol. Endogenous opioid peptides may be involved in mediating taste responses and preferences for palatable foods, notably those rich in sugar and fat.
\end{abstract}

$\begin{array}{lccccc}\text { Endogenous opioid peptides } & \text { Naloxone } & \text { Butorphanol } & \text { Obesity } & \text { Binge eating } & \text { Taste response } \\ \text { Food consumption } & \text { Sugar } & \text { Fat } & & & \end{array}$

ENDOGENOUS opioid peptides are involved in the regulation of energy intakes in both humans and rats $(15,58,63)$. Several studies have shown that opioid antagonists naloxone and naltrexone reduced intakes of laboratory chow in both rats and mice $(11,35,37,55)$. Central administration of selective antagonists of mu, kappa, and delta receptors also caused reductions in food intake of laboratory rats $(38,43,45)$. The administration of opioid agonists had the reverse effect. Such agonists as morphine or butorphanol increased food intakes in rats $(15,31,32,66)$. Agonists of specific opioid receptors, including mu, kappa, and delta, also stimulated food intakes in laboratory rats $(31,33,38$, $56,57,64)$.

In clinical studies, the opioid antagonist naloxone reduced food consumption of normal-weight and obese subjects $(6,13$, $70,73)$ and diminished the size of binge-eating bouts in female bulimics (52). Naltrexone also had the effect of reducing food consumption in obese humans $(7,68)$. The opposite effects on food intake were obtained with the opioid agonist butorphanol. In the one study published, injections of butorphanol led to an increase in food intake as measured over a 6-h period, an effect that was blocked by naloxone (59).

The effects of opioid peptides on food intake appear to be strongest for the most palatable foods. Those animal studies that compared the effects of opioid antagonists across diets $(3,47)$ found that naloxone and naltrexone caused greater reductions in the intake of palatable cafeteria diets as compared to laboratory chow. Other studies addressed the effects of opioid peptides on the consumption of two palatable dietary ingredients: sugar and fat. Naloxone suppressed stress-induced sucrose hyperphagia $(8,55)$ and selectively reduced intakes of carbohydrate and fat in a dietary self-selection paradigm (49). Conversely, the agonists morphine (50) and butorphanol (64) selectively increased fat consumption. Some investigators have proposed that the primary role of the opioid peptide system is in mediating overeating that is associated with exposure to palatable (47) or high-fat foods (64).

Opioid peptides may thus influence energy intakes by mediating the pleasure response to foods (42). Sensory preferences for sweet taste, in particular, appear to be under opioid control. It may be that opioid blockade renders palatable foods less rewarding $(15,63)$. In studies with rats, opioid antagonists were most effective in reducing intakes of palatable sweet liquids such as glucose, sucrose or saccharin solutions $(36,41,45,54)$. Conversely, morphine enhanced preferences for sweet taste (12) and stimulated the intake of sweet solutions. Central administration of mu and delta receptor agonists also increased intakes of

\footnotetext{
${ }^{1}$ Supported by U.S. Public Health Service Grants DA05471, DK38073 and CRC Grant 5MO1RR00042.

${ }^{2}$ Requests for reprints should be addressed to Adam Drewnowski, Human Nutrition Program, School of Public Health M-5170, University of Michigan, Ann Arbor, MI 48109-2029.
} 
saccharin solutions in rats (34). Furthermore, mice deficient in opioid receptors displayed a reduced preference for the sweet taste of saccharin (76).

Further support for the opioid mediation of food reward is provided by clinical reports that oral doses of naltrexone reduced pleasantness ratings of glucose solutions and diminished the acceptability of food odors (26). Another study showed that opioid antagonist nalmefene selectively reduced intake of the most preferred foods during a lunch meal (75). However, since most previous studies focused on opioids and sweet taste, there are as yet no data, either in animals or humans, regarding opioid effects on sensory preferences for stimuli containing both sugar and fat. It is also unclear whether opioid antagonists would most effectively reduce the consumption of foods containing sugar or fat, or those foods that are most preferred, regardless of their nutrient composition.

If the effects of opioid antagonists on food intake are secondary to a reduction in food palatability, then we should expect to see changes in taste preference profiles as well as in food consumption. Accordingly, we compared the effects of naloxone and butorphanol infusions on taste preferences for a range of stimuli containing sugar and fat. Taste responsiveness profiles have been used in previous studies to distinguish between relative preferences for sugar versus fat among obese, anorectic and bulimic patients (18-21). While obese women preferred moderately sweet but high-fat stimuli (19), anorectic patients liked intense sweetness but showed an aversion to the oral sensation of dietary fat (21).

The choice of sugar/fat mixtures as sensory stimuli was suggested by previous research on taste preferences (18-21). Sweet high-fat foods are universally regarded as highly palatable and are a frequent target of food cravings. Specific cravings for such foods as chocolate, cookies or ice cream have been reported by obese patients (74), by patients with seasonal affective disorder (65), and following treatment with antidepressants $(27,61)$. Although such cravings have been termed "carbohydrate cravings" by some investigators (74), the fact is that chocolate, cookies and ice cream are palatable sweet mixtures of two key ingredients: sugar and fat (16).

Clinical observations and anecdotal reports suggest further that the compulsive eating bouts in bulimia nervosa often involve the same dessert-type foods, rich in both sugar and fat $(17,51)$. Given the connection to food cravings, we hypothesized that the most pronounced effects of opioid peptides would be obtained for palatable foods that are mixtures of sugar and fat.

Taste preference profiles may be predictive of food choice and actual food consumption. To examine the effects of naloxone and butorphanol infusions on caloric intakes, we provided the subjects with a choice of palatable snack foods of varying sugar and fat content. If opioid effects on food intake are nutrient specific, then the consumption of foods rich in sugar or fat should be affected the most. Conversely, if opioid antagonists reduce the reward value of the most preferred foods, most pronounced effects should be obtained for the most highly rated foods, independent of their nutrient composition (75).

While opioid mechanisms may not be central to normal food intake, they may be important in mediating binge-eating episodes among susceptible individuals. In past clinical studies, abnormal opioid peptide levels have been observed among both obese and eating-disordered women characterized by a pattern of binge eating $(30,40)$. Accordingly, we examined the effects of naloxone and butorphanol on taste preferences and food consumption patterns in compulsive binge eaters and in normalweight female controls. Our hypothesis was that the effects of opioid peptides on taste preferences and food choice would be
TABLE

SUMMARY OF SUBJECT CHARACTERISTIC

\begin{tabular}{lcc} 
& $\begin{array}{c}\text { Binge Eaters } \\
(\mathrm{n}=14)\end{array}$ & $\begin{array}{c}\text { Contros } \\
n=12)\end{array}$ \\
Age (years) & $26.3(2.0)$ & 16.912 .61 \\
Height $(\mathrm{cm})$ & $160.4(1.2)$ & $63.711 .8)$ \\
Weight $(\mathrm{kg})$ & $80.0(6.2)$ & $22.7(0.6)$ \\
BMI $\left(\mathrm{kg} / \mathrm{m}^{2}\right)$ & $30.9(2.2)$ & $12.111 .1)$ \\
Restraint score & $23.4(1.1)$ & \\
\hline
\end{tabular}

Data are means and SEMs (in parentheses).

more pronounced among women with eating disorders than among female controls.

METHOD

\section{Subjects}

Women subjects, 18 to 40 years old, were recruited through advertisements placed in community newspapers. Fourteen of the subjects were self-reported binge eaters. Confirmatory diagnosis of binge eating was made during a clinical interview based on responses to questions regarding DSM-III-R bulimia nervosa (2) contained in the Diagnostic Survey of Eating Disorders (39) and the structured clinical interview (SCID). Twelve out of 14 binge eaters fulfilled DSM-III-R criteria for bulimia nervosa, while the remaining 2 reported frequent binging without purging. None of the 14 binge eaters was a patient at the University Hospital Eating Disorders Clinic and none had a prior history of anorexia nervosa. However, 8 binge eaters had prior histories of depression and one had a history of chemical dependency in remission. Eight out of 14 binge eaters were obese. Obesity was defined as body mass index $\left(\mathrm{BMI}=\mathrm{kg} / \mathrm{m}^{2}\right)$ in excess of 28.0 . Mean weight for the group was $80.0 \mathrm{~kg}$. Physical examination and laboratory data revealed no evidence of abnormalities requiring exclusion such as gastrointestinal or endocrine dysfunction. None of the subjects was on medication. All binge eaters reported regular menstrual cycles.

Control subjects $(N=12)$, also recruited through advertisements, were of normal weight and had no history of binge eating. These subjects were between 90 and $110 \%$ of median weight for height from NHANES II data (1), were not currently dieting to lose weight, and had no prior history of an eating disorder as determined by the structured clinical interview (SCID). Physical examination and laboratory data were routine. The subjects had regular menstrual periods and were not on medication. Both binge-eating and normal women were tested in the follicular phase of their menstrual cycle, with all tests completed in the first 10 days of the cycle. All subjects signed the informed consent form and all protocols had been approved by IRB at the University of Michigan. The subjects were compensated for completing the study. Subject characteristics are summarized in Table 1 .

\section{Drugs}

The drugs were opioid antagonist naloxone, opioid agonist butorphanol tartrate, and saline placebo. Naloxone, a short-lasting opioid antagonist, was administered as a 6 - $\mathrm{mg}$ bolus followed by $0.1-\mathrm{mg} / \mathrm{kg} / \mathrm{h}$ intravenous drip for $2.5 \mathrm{~h}$. The same dose of naloxone had been used to decrease size of binges in bulimic women (52). Butorphanol, a synthetic mixed agonist/antagonist. 
was administered as a $1-\mu \mathrm{g} / \mathrm{kg}$ bolus followed by IV saline drip. This dose had been shown to increase food intake in one previous study (59). Apart from causing sleepiness in one subject, this dose had no observable side effects. Since drug doses were calculated per kilogram of body weight, obese binge eaters received higher absolute doses of the two drugs than did normalweight binge eaters or normal-weight controls. It may be that body weight per se affects the response to opioid manipulations. However, data analyses showed that there was no difference in drug effects on food intake between the present samples of obese $(n=8)$ and normal-weight $(n=6)$ binge eaters. All binge eaters $(n=14)$ were therefore treated as a single group.

\section{Sensory Stimuli}

Sensory stimuli were 20 samples of sweetened commercial dairy products of varying sugar and fat content. These included whole milk ( $3.5 \%$ fat), half and half ( $10 \%$ fat), light cream (20\% fat) and heavy cream ( $36.0 \%$ fat), sweetened with $2,4,8$, 16 and $32 \%$ sucrose in a $4 \times 5$ factorial design. Sucrose levels were set weight by weight (wt./wt.) rather than weight by volume (wt./vol.) in order to provide a direct means of comparison to previous studies on liquid and solid foods (24). The stimuli, chilled to $5^{\circ} \mathrm{C}$, were presented to subjects in $10-\mathrm{ml}$ plastic cups and in a random order for taste and hedonic evaluations. The subjects tasted each sample and rated it on four 9-point category scales. For the scaling of acceptability or hedonic preference, the subjects used a fully anchored 9-point hedonic preference scale (20), ranging from "dislike extremely" to "like extremely." For the scaling of sweetness, creaminess and fat content, the subjects used three unipolar category scales, with each quality ranging from "absent" to "extreme." Following previous procedures, the subjects were instructed to taste each stimulus, expectorate, and rinse their mouths with water between samples.

\section{Food Stimuli}

Food stimuli were 16 common snack foods containing different amounts of sugar and fat (62). Their caloric density and nutrient composition as percent calories are shown in Table 2. Foods in Category 1 were low in both sugar and fat. Category 2 foods were low in sugar but high in fat. Category 3 foods were sweet but low in fat. Category 4 foods were high in both sugar and fat.

On a day prior to testing, the subjects indicated how much they liked each of the 16 foods using a food preference checklist and a 9-point category scale. Mean hedonic ratings for the 16 foods are shown in Table 2, averaged across the entire subject population $(n=26)$. During drug infusion, each subject was presented with those 8 foods ( 2 from each category), which she herself had rated most highly. Thus each subject was offered those foods she regarded as most palatable, and no subject was presented with foods she disliked. The foods were presented in $100-\mathrm{kcal}$ portions. The subjects were told that they could eat any food on the tray in any order they liked. If they ate the entire 100 -kcal portion, another portion would be provided by the experimenter.

\section{Internal States}

Acute changes in perceived hunger, fullness and nausea were assessed every $30 \mathrm{~min}$ during drug infusion. The subjects rated their status using 5-point category scales: 5-inch lines separated into 1-inch intervals and anchored at each end with statements ranging from "not at all " to "extremely "

\section{Experimental Protocol}

The study followed a double-blind within-subjects design. Each subject received all three drug or placebo infusions, ad-
TABLE 2

FOODS AVAILABLE FOR CONSUMPTION A SUMMARY OF FOOD CHOICES

\begin{tabular}{lrrrrr}
\hline & $\begin{array}{c}\text { Hedonic } \\
\text { Rating }\end{array}$ & $\begin{array}{c}\text { kcal per } \\
\text { Portion }\end{array}$ & \multicolumn{2}{c}{$\begin{array}{c}\text { Macronutrient } \\
\text { Content (kcal) }\end{array}$} \\
\hline Category 1: low sugar/low fat & & & CHO & PRO & Fat \\
Popcorn & 7.19 & 101 & 79 & 12 & 9 \\
Saltines & 6.19 & 94 & 72 & 9 & 19 \\
Breadsticks & 5.69 & 99 & 79 & 12 & 9 \\
Pretzels & 6.65 & 109 & 84 & 7 & 8 \\
Category 2: low sugar/high fat & & & & & \\
Fritos & 5.69 & 98 & 41 & 4 & 55 \\
Cream cheese + saltines & 4.50 & 101 & 20 & 8 & 72 \\
Potato chips & 6.57 & 101 & 38 & 4 & 58 \\
Lorna Doones & 6.16 & 96 & 58 & 4 & 38 \\
Category 3: high sugar/low fat & & & & & \\
Jelly beans & 4.84 & 100 & 100 & 0 & 0 \\
Marshmallows & 4.84 & 99 & 97 & 3 & 0 \\
Jello & 5.27 & 100 & 100 & 0 & 0 \\
Jelly + saltines & 4.42 & 109 & 93 & 2 & 5 \\
Category 4: high sugar/high fat & & & & & \\
Chocolate chip cookies & 7.73 & 109 & 55 & 4 & 41 \\
Snickers bar & 6.73 & 105 & 48 & 10 & 43 \\
M\&M candies & 7.77 & 100 & 54 & 5 & 41 \\
Oreo cookies & 6.61 & 96 & 58 & 4 & 38 \\
\hline
\end{tabular}

ministered in a random order and at least two days apart. On each infusion day, the subjects presented to the Clinical Research Center at $8 \mathrm{a} . \mathrm{m}$. after fasting since $10 \mathrm{p} . \mathrm{m}$. the previous night. An intravenous catheter was placed in the arm vein, and saline infusion was started at that time. At 8:30 a.m., the subjects first rated their hunger, fullness and nausea using category scales. The subjects were then presented with the first set of 20 taste stimuli for sensory and hedonic evaluations (pretreatment baseline). Drug infusions began at 9 a.m. The second set of taste responses was obtained after $1 \mathrm{~h}$ of infusion (posttreatment). Ratings of internal states were repeated every 30 minutes during the infusion. At 10:30 a.m., the subjects were presented with 8 foods on a tray and were allowed to select and consume the foods ad lib for a period of $1 \mathrm{~h}$. The trays were removed and drug infusion was stopped at 11:30 a.m.

\section{Data Analyses}

Hedonic responses and ratings of perceived sweetness, creaminess and fat content of taste stimuli were first analyzed using a five-way BMDP ANOVA for repeated measures. Subject grouping (binge eaters versus controls) was a between-subjects variable, while drug type (butorphanol, naloxone or saline), drug treatment (pre- vs. posttreatment), and fat and sugar content of sensory stimuli all served as within-subjects variables. Separate analyses of variance were also conducted for each drug in turn. Additional analyses of variance were conducted to compare hedonic preferences profiles of binge eaters and normal-weight controls in the baseline (i.e., pretreatment) condition.

Analyses of variance followed by Dunnett's $t$-tests were used to compare caloric intakes between the drug and the saline conditions. Anovas were conducted for the total calories consumed during the allowed 1-h period, and for calories by food category 

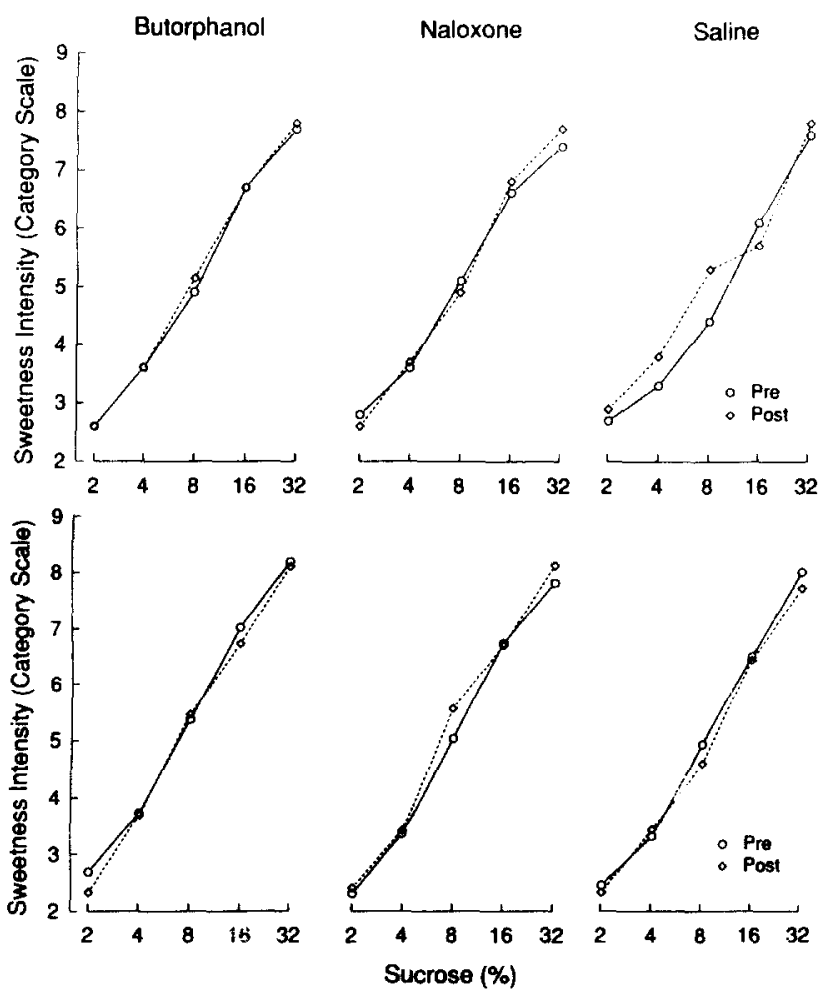

FIG. 1. Perceived sweetness ratings for binge eaters (top) and controls (bottom) as a function of sucrose levels before and after drug infusion. The data are shown separately for the three drug conditions.

(1 through 4) and by macronutrient content (carbohydrate, protein and fat). Comparisons between binge eaters and controls were made by $t$-tests.

To determine whether opioid effects varied with nutrient composition or the palatability of the food, all snacks were arranged in rank order of hedonic preference. Spearman correlation coefficients were used to link preferences with the magnitude of drug effects. Analyses of internal states (hunger, fullness, nausea) were made using BMDP ANOVA for repeated measures, with subject group, drug and time as independent variables.

\section{RESULTS}

\section{Taste Perceptions}

All subjects correctly rated increasing sweetness of taste stimuli. As in past studies (18-21), sweetness intensity ratings rose monotonically with increasing stimulus sucrose levels. Figure 1 shows sweetness intensity ratings of binge eaters (top panel) and controls (bottom panel) as a function of sucrose levels, separately for each drug type, before and after drug infusion. A five-way analysis of variance showed significant main effects of sugar, $\mathrm{F}(4,96)=303.2, p<0.01$, and fat, $\mathrm{F}(3,72)=$ $7.16, p<0.01$. Sweetness intensity ratings did not differ between binge eaters and controls (main effect of group: $F<1$, ns). Similarly, sweetness intensity ratings were not affected by drug treatment, $F(1,24)=2.20$, ns. Separate ANOVAs of sweetness ratings conducted for each drug type revealed significant main effects of sugar, fat, or both, but no main effect of diagnostic group and no main effect of drug treatment.

Sensory assessments of stimulus creaminess also rose with increasing stimulus fat content. Figure 2 shows creaminess ratings of binge eaters (top panel) and controls (bottom panel) as a

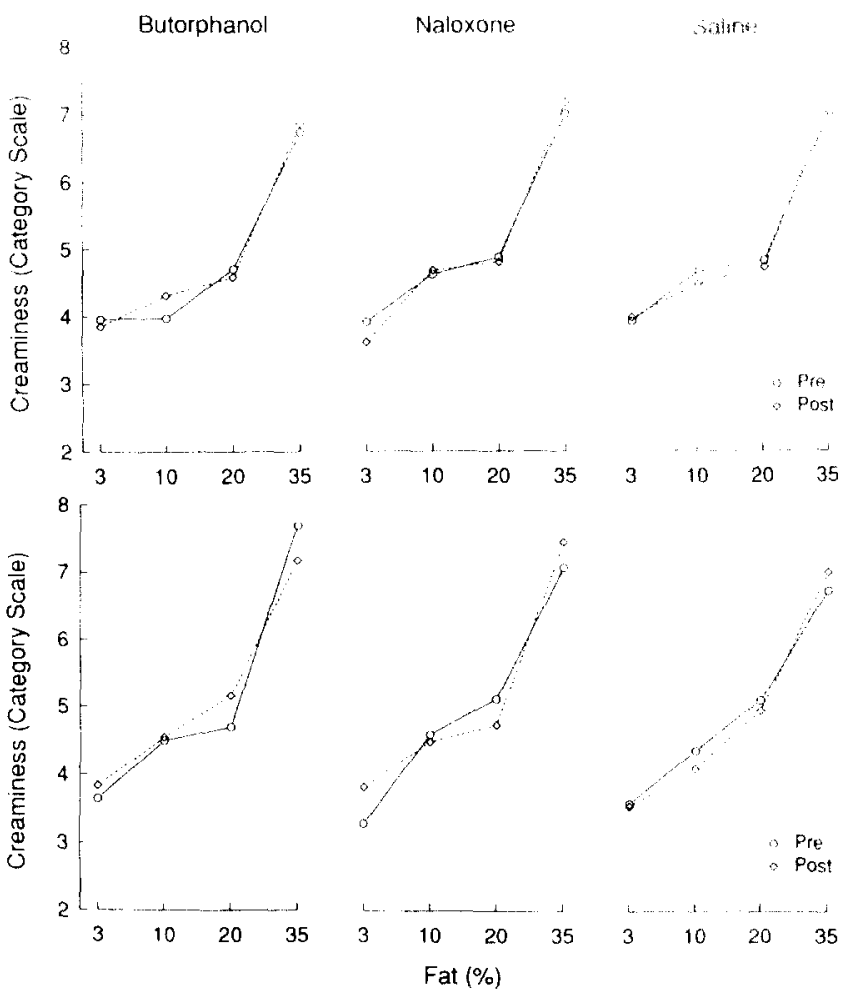

FIG. 2. Perceived creaminess ratings for binge eaters (top) and controls (bottom) as a function of sucrose levels before and after drug infusion. The data are shown separately for the three drug conditions.

function of stimulus fat content, separately for each drug, before and after drug infusion. Five-way analysis of variance showed significant main effects of fat, $\mathrm{F}(3,72)=93.51, p<0.01$, and sugar, $F(4,96)=26.85, p<0.01$. However, no main effects of subject group, drug type or drug treatment were observed. Separate ANOVAs conducted for each drug type in turn showed the expected significant main effects of fat and sugar, but no main effect of subject group or drug treatment.

Similar results were obtained for sensory assessments of fat content. The main effects of fat, $\mathrm{F}(3,72)=110.18, p<0.01$, and sugar, $\mathrm{F}(4,96)=10.79, p<0.01$, were both significant. However, no main effects of group, drug type or drug treatment were observed. Separate ANOVAs conducted for each drug type showed significant main effects of both fat and sugar, but no main effect of subject group and no main effect of drug treatment. Thus drugs had no effect on sensory functioning and did not affect the subjects' perception of the sweetness or fat content of taste stimuli.

\section{Taste Preference Profiles}

Hedonic response profiles of binge eaters and controls in the baseline (i.e., pretreatment) condition are summarized in Fig. 3. Analysis of baseline data showed significant main effects of sugar, $\mathrm{F}(4,96)=6.96, p<0.01$, and fat, $\mathrm{F}(3,72)=7.74, p<0.01$. Binge eaters showed higher preference ratings for more intensely sweet solutions: the sugar by group interaction was significant, $\mathrm{F}(4,96)=2.64, p<0.05$. In contrast, binge eaters did not differ from controls in their preferences for stimulus fat; the fat by group interaction was not significant, $F(3,72)=1.22$, ns.

As in previous studies (18-21), hedonic preference ratings followed an inverted- $U$ shape, with peak preferences obtained at 


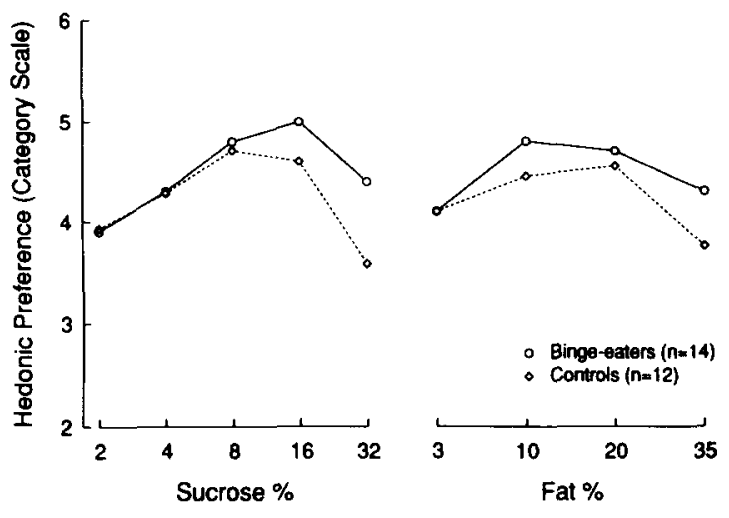

FIG. 3. Hedonic preference profiles of binge eaters and controls at baseline as a function of stimulus sucrose (left) and fat content (right panel).

an optimum point or breakpoint. For normal controls, this breakpoint was observed at $8 \%$ sugar and $20 \%$ fat. Binge eaters tended to prefer stimuli that were more intensely sweet $(16 \%$ sucrose), again in agreement with previous results $(17,18)$.

\section{Opioid Effects on Taste Preferences}

Naloxone infusions significantly reduced hedonic preferences for the sugar/fat mixtures. As shown in Fig. 4, preference ratings declined as a function of both sugar and fat content. This effect was observed equally for binge eaters and for controls. In contrast, the effects of butorphanol were more complex. Butorphanol appeared to reduce hedonic preferences in binge eaters but to increase them in controls. Saline placebo had no effects. Five-way analysis of variance showed a significant drug type by treatment (pre-post) interaction, $\mathrm{F}(1,24)=4.83, p<0.01$, confirming that different drugs had distinct effects on taste preferences. The finding that binge eaters and controls differed in their response to butorphanol was confirmed by a significant group by drug type by treatment interaction, $\mathrm{F}(2,48)=3.45, p<0.05$. As expected, main effects of sugar, $\mathrm{F}(3,72)=6.15, p<0.01$, and fat, $F(4,96)=6.22, p<0.01$, were significant as well.

Analyses of preference scores were also conducted for each drug in turn. Analyses of naloxone data showed a significant main effect of drug treatment, $F(1,24)=6.43, p<0.01$, but no group by treatment interaction. These results suggest that taste preferences of binge eaters and controls were equally affected by naloxone. As expected, the main effect of sugar was significant as well, $\mathrm{F}(4,96)=4.00, p<0.01$.

Analyses of butorphanol data showed no main effect of drug treatment on taste preferences. The expected group by treatment interaction was only marginal, $\mathrm{F}(1,24)=3.89,0.05<p<0.10$. Main effects of sugar, $\mathrm{F}(4,96)=5.29, p<0.01$, and fat, $\mathrm{F}(3,72)=$ $6.20, p<0.01$, were both significant. Data analyses for saline placebo showed no main effects of either group or drug treatment. Only the main effects of sugar, $\mathrm{F}(4,96)=5.54, p<0.01$, and fat, $F(3,72)=5.75, p<0.01$, were significant.

Additional ANOVAs for each drug were conducted separately for bingc eaters and controls. For binge eaters, the main effect of drug treatment was obtained only for naloxone, $F(1,13)=$ $7.71, p<0.05$, but not for saline or butorphanol. There was also a significant treatment by fat by sugar interaction, $F(12,156)=$ $1.86, p<0.05$. For controls, main drug treatment effect was obtained only for naloxone, $\mathrm{F}(1,11)=3.98, p<0.05$, one-tailed, but not for saline or butorphanol.
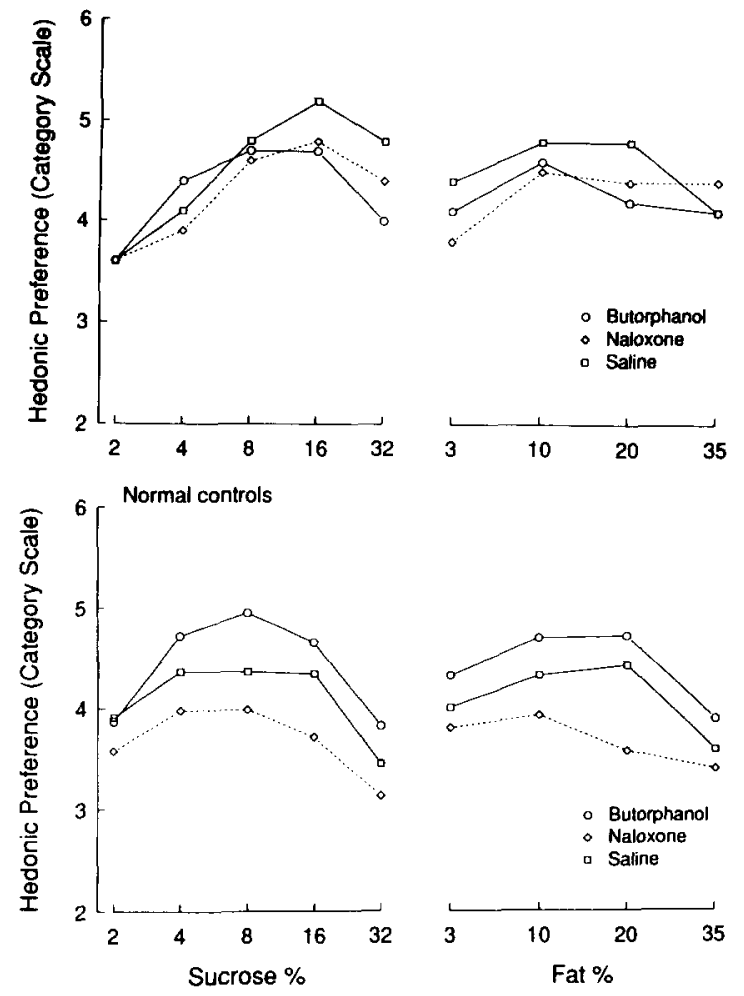

FIG. 4. Hedonic preference profiles of binge eaters (top) and controls (bottom) as a function of drug infusion. The data are shown as a function of stimulus sucrose (left) and fat content (right panel).

\section{Opioids and Food Consumption}

Food consumption data are summarized in Table 3 . Control women consumed a mean of $505 \mathrm{kcal} / \mathrm{h}$ when infused with saline placebo. The largest proportion of calories derived from high-fat foods in Category 2 and from sweet high-fat foods in Category 4. Although naloxone reduced snack consumption (397 vs. $505 \mathrm{kcal}$ ), the difference in calories was not statistically significant, Dunnett's $t(3,22)=1.96,0.10>p>0.05$. Butorphanol had no effects on food consumption.

Binge eaters consumed somewhat more calories during the saline condition than did controls $(694$ vs. $505 \mathrm{kcal})$, but the difference was not statistically significant, $t(24)=1.31, p>0.05$. Most calories were derived from high-fat foods in Category 2 and sweet high-fat foods in Category 4 . Naloxone infusions significantly reduced total caloric intakes relative to the saline condition, Dunnett's $t(3,26)=3.07, p<0.01$. The reduction in calories was significant only for sweet high-fat foods in Category 4 , Dunnett's $t(3,26)=3.24, p<0.01$. Butorphanol again had no effects on the binge eaters' food consumption.

Nutrient composition of foods consumed by binge eaters and controls is summarized in Table 4. Naloxone-mediated reduction in caloric intake did not appear to be macronutrient specific. Intakes of protein, carbohydrate and fat were all significantly reduced in binge eaters. For normal controls, only fat intake was significantly reduced, when tested with a one-tailed test, Dunnett's $t(3,22)=2.29, p<0.05$.

The effects of naloxone on the consumption of individual foods are shown in Fig. 5. Caloric intake of each food under naloxone is expressed as percent of caloric intake for that food in the saline placebo condition. The average percent change for 
TABLE 3

SUMMARY OF FOOD CONSUMPTION PATTERNS FOR BINGE EATERS AND CONTROLS AS A FUNCTION OF DRUG INFUSION

\begin{tabular}{lrrr} 
& Butorphanol & Naloxone & Saline \\
\hline & & & \\
Binge eaters & & & \\
Category 1: low sugar/low fat & $128(39)$ & $87(33)$ & $95(20)$ \\
Category 2: low sugar/high fat & $157(52)$ & $144(53)$ & $226(56)$ \\
Category 3: high sugar/low fat & $70(20)$ & $65(16)$ & $112(26)$ \\
Category 4: high sugar/high fat & $161(49)$ & $121(51)^{*}$ & $261(69)$ \\
& & & \\
Total (kcal/h) & $518(103)$ & $417(101)^{*}$ & $694(121)$ \\
Normal controls & & & \\
Category 1: low sugar/low fat & $87(20)$ & $107(22)$ & $105(18)$ \\
Category 2: low sugar/high fat & $193(50)$ & $140(36)$ & $195(38)$ \\
Category 3: high sugar/low fat & $72(27)$ & $49(17)$ & $55(17)$ \\
Category 4: high sugar/high fat & $143(30)$ & $102(33)$ & $143(30)$ \\
Total (kcal/h) & $496(83)$ & $397(76)$ & $505(66)$ \\
\hline
\end{tabular}

Data are means $(\mathrm{kcal} / \mathrm{h})$ and SEMs

${ }^{*} p<0.05$; Dunnett's $t$-test.

nonsweet, nonfat foods (Category 1) was $-4 \%$, that is, a small net increase. In contrast, net reduction in calories was $29 \%$ for high-fat foods (Category 2); 39\% for sweet foods (Category 3); and $54 \%$ for sweet high-fat foods (Category 4 ).

There was no significant correlation between the magnitude of naloxone effects and the foods' palatability ratings as judged by the subjects $(r=.10 ; n s)$. Intake of some of the most highly rated foods (e.g., popcorn) was not altered by naloxone.

\section{Internal States}

Measures of internal states obtained at 30-minute intervals during drug infusion are summarized in Fig. 6. As expected, hunger decreased and fullness increased following the consumption of snack foods. Anova for repeated measures showed significant main effects of time for both hunger, $F(5,120)=32.63$, $p<0.01$, and fullness ratings, $\mathrm{F}(5,120)=47.06, p<0.01$. In contrast, ratings of nausea did not change with time, $F(5,120)=$ 1.42 , ns. Hunger and fullness ratings for binge eaters did not change as much following snack ingestion, reflecting potential difficulties in interoceptive awareness.

TABLE 4

MACRONUTRIENT CONTENT OF FOODS CONSUMED BY BINGE EATERS AND CONTROLS AS A FUNCTION OF DRUG INFUSION

\begin{tabular}{lccc}
\hline & Butorphanol & Naloxone & Saline \\
\hline Binge eaters & & & \\
$\quad$ Carbohydrate & $320(57)$ & $253(52)^{*}$ & $422(69)$ \\
Protein & $29(6)$ & $22(5)^{*}$ & $34(7)$ \\
Fat & $169(46)$ & $142(48)^{*}$ & $237(51)$ \\
Normal controls & & & \\
$\quad$ Carbohydrate & $293(54)$ & $239(45)$ & $292(35)$ \\
Protein & $25(4)$ & $22(4)$ & $27(4)$ \\
Fat & $178(35)$ & $136(32) \dagger$ & $186(33)$ \\
\hline
\end{tabular}

Data are means $(\mathrm{kcal} / \mathrm{h})$ and SEMs.

${ }^{*} p<0.05$; Dunnett's test, two-tailed, †one-tailed.
Naloxone intake as $\%$ of placebo

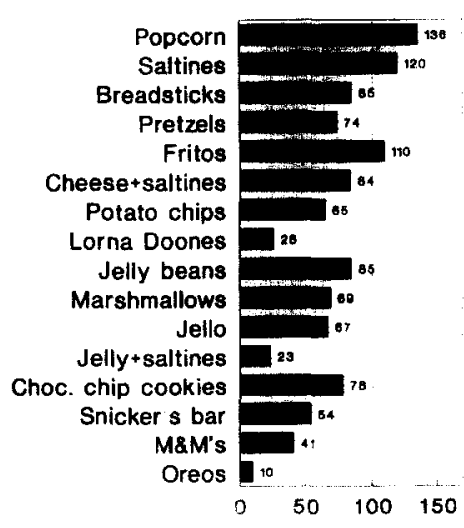

FIG. 5. Mean intakes of different foods by naloxone-treated subjects $(n=26)$ expressed as percentage of intakes under saline placebo

Drug infusions did not alter hunger or fullness ratings. The effects of naloxone or butorphanol on the perception of hunger or fullness were not significant. The overall effect of drug condition on ratings of nausea was significant, $\mathrm{F}(2,48)=6.12, p<0.01$. When controls and binge eaters were analysed separately, the effect of drug condition was significant only for binge eaters, $F(2,26)=5.65, p<0.01$, but not for controls, $F(2,22)=2.30$, ns.

\section{DISCUSSION}

Opioid-mediated reduction in food intake may be secondary to changes in taste preferences and the reward value of food. The opioid antagonist naloxone significantly reduced taste preferences for sugar/fat sensory stimuli in female binge eaters and in controls. Naloxone also significantly reduced the consumption of sweet high-fat foods in binge eaters, though not in controls. Strongest effects of naloxone in reducing caloric intake were obtained for the food group composed of M\&M candies, Snickers bars, and Oreo and chocolate chip cookies (Category 4). As noted previously, such foods are among the most common targets of food cravings, and figure prominently in reports of eating binges in obesity and bulimia nervosa $(22,71)$. Hunger and fullness ratings were not affected by naloxone infusions, arguing against the notion that opioid antagonists modulate hunger and satiety as applied to normal feeding.

Taste responsiveness profiles are a direct measure of food palatability and have been used to predict food preferences and food consumption (60). However, our data do not wholly support the hypothesis that the effects of naloxone should be maximal for the most preferred foods, regardless of their nutrient composition. Although cookies and chocolate (both Category 4 foods) were highly preferred, the subjects gave almost equally high ratings to saltines and popcorn. While the consumption of Category 4 foods was significantly reduced by naloxone, the consumption of popcorn was, on the contrary, increased. In contrast to a study by Yeomans (75), our data failed to show a significant correlation between naloxone-induced reduction in food intake and self-reported food preferences, also established using a standard food checklist. However, it should be noted that the snack foods in our study were specifically selected for their high palatability, and the subjects were not offered any of the foods they disliked. As a result, our study design did not allow for a powerful contrast between preferred and nonpreferred foods. 

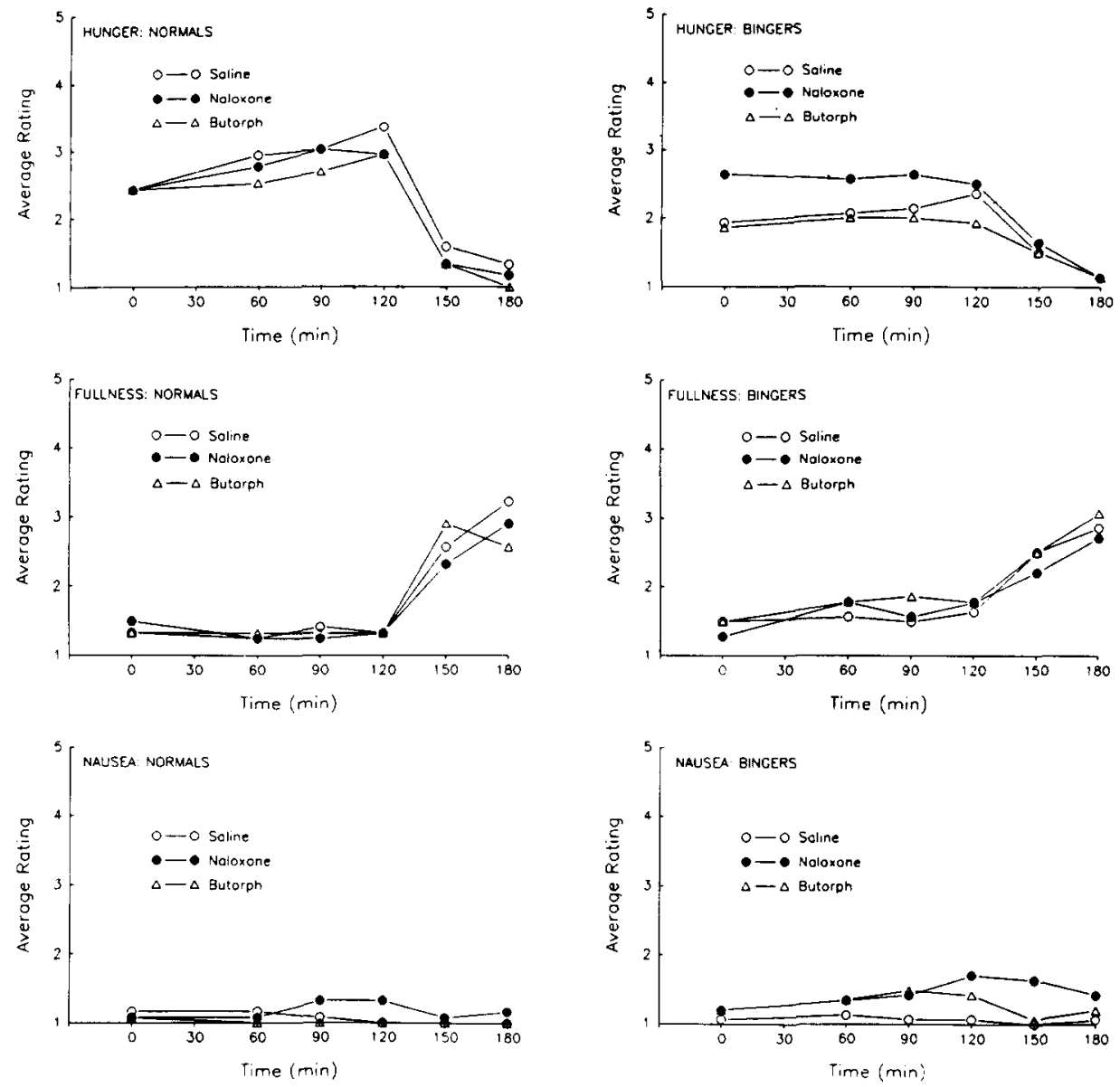

FIG. 6. Ratings of internal states: hunger, fullness and nausea as rated by subjects at 8:30 a.m. and at 30-min intervals during drug infusions. The data are shown for binge eaters (right panels) and controls (left panels).

Opioid effects did not appear to be macronutrient specific. In contrast to some animal studies $(49,50)$, naloxone did not selectively reduce the intake of any one macronutrient. The reduction in caloric intake in binge eaters was associated with significant reductions in calories from carbohydrate, protein, and fat. Only the reduction in fat calories was significant for control women, most likely because foods in the affected Categories 2 and 4 were rich in fat.

The present data suggest that some palatable foods are more sensitive to opioid antagonism than are less-preferred foods. Although several past studies have demonstrated significant opioid effects on "normal" foods such as sandwiches, the present study indicates that foods rich in sugar and fat may be affected the most. The difference is most likely that of degree rather than specific food type. However, it should also be noted that all foods in Category 4 contained chocolate. Chocolate cravings have been observed in obesity and eating disorders $(51,74)$, seasonal affective disorder (SAD) (65), as a function of the menstrual cycle (69) and in the course of antidepressant treatment (61). The potential connection between opioid peptides and preferences for chocolate is the subject of continuing investigation.

If opioid antagonists primarily reduce that part of overeating that is due to palatable foods, then most pronounced effects of naloxone might be expected among those subjects who are most vulnerable to challenge with palatable diets. Both obese and normal-weight binge eaters report a pattern of compulsive overeating that can be triggered by palatable foods. Our data showed that the naloxone more effectively reduced food intakes among binge eaters as compared to normal-weight controls. Consequently, the main therapeutic value of opioid antagonists may be in reducing binge-eating episodes and not in the long-term control of body weight.

The present observations may thus help explain why treatment with opioid antagonists has failed to induce weight loss in many obese individuals. Clinical studies have shown that naloxone reduced food intakes of obese and normal-weight subjects $(6,13,52)$. Chronic treatment with naltrexone, a longer-lasting opioid antagonist, also suppressed food intakes of obese patients during a lunch meal (68). However, body weights were for the most part unaffected by chronic naltrexone treatments $(7,46$, 53). Given their undesirable effects on liver function, high doses of opioid antagonists are not currently viewed as potential therapy adjuncts for weight reduction $(7,53)$.

Contrary to our predictions, butorphanol had no significant effects on food consumption. In one previous study (52), butorphanol injections increased the consumption of ham, jelly and peanut butter sandwiches over a 6-h time period. In our study, 
butorphanol had no effect on food consumption; however, data were collected only over a 1 -h period. Although butorphanol increased taste preferences of control women, it reduced taste preferences of bulimics, though not significantly so. However, it should be noted that butorphanol has a mixed agonist/antagonist activity. If the opioid peptide system in binge eaters is abnormal, the antagonist qualities of butorphanol might become more apparent than they would be in controls. Specifically, if compulsive eating of preferred foods by binge eaters is more "opioid mediated," then these subjects might be more sensitive to the opioid antagonist qualities of butorphanol. Still, it is unclear why butorphanol failed to stimulate intake of preferred foods at a dose equal to that used in a previous study (52). It may be that other opioid agonists, including delta and mu receptor agonists, are likely to be more successful in mediating palatability-induced food consumption.

The present results suggest that abnormalities in the endogenous opioid peptide system may be linked to elevated sensory preferences for sugar/fat mixtures and compulsive overeating of sweet high-fat foods. Abnormal opioid peptide levels have been observed in obese rats (48), and among obese and anorectic women $(30,40)$. Additional studies suggest that the consumption of palatable foods may in turn influence the endogenous opioid peptide system. It is interesting to note that mosi dietary manp. ulations of endogenous opioid peptide levels hatve employed preparations of fat, sugar, or both. In one study 25.5 , the 601 sumption of chocolate milk or chocolate candy by rats caused increased release of beta-endorphin. In other studies, infusion: of sucrose solutions or fat emulsions increased analgesia thresholds in infant rats, suggesting an increase in opioid release $(10,67)$. These effects may be linked to the acquisition of food preferences: some investigators have proposed that opioid release might sustain ingestive behavior and lead to development of sweet preferences (9). Similar findings have heen obtained in human studies $(28,29)$.

Obvious parallels have also been drawn between binge eating and drug addiction, since both behavioral syndromes involve intense cravings and loss of control. It may be that the same physiological mechanisms are involved in mediating food cravings and drug reward. Both clinical observations and anecdotal reports indicate that sweet cravings are often associated with opiate addiction (72), while opiate withdrawal is sometimes eased by sweets (54). The present study provides preliminary evidence in favor of the hypothesis that food cravings in obesity and eating disorders may be mediated by the endogenous opioid peptide system.

\section{REFERENCES}

1. Abraham, S. Obese and overweight adults in the United States. Vital and health statistics 11 (230), DHHS Publ. 83-1680. Washington, DC: PHS; 1983.

2. American Psychiatric Association. Diagnostic and statistical manual of mental disorders. 3rd edition (revised). Chicago, IL: APA Press: 1988.

3. Apfelbaum, M.; Mandenoff, A. Naltrexone suppresses hyperphagia induced in the rat by a highly palatable diet. Pharmacol. Biochem. Behav. 15:89-91; 1981.

4. Arjune, D.; Bodnar, R. J. Suppression of nocturnal, palatable and glucoprivic intake by the k-opioid antagonist, nor-binaltorphimine. Brain Res. 534:313-316; 1990.

5. Arjune, D.; Standifer, K. M.; Pasternak, G. W.; Bodnar, R. J. Reduction by central beta-funaltrexamine of food intake in rats under freely-feeding, deprivation and glucoprivic conditions. Brain Res. 535:101-109; 1990.

6. Atkinson, R. L. Naloxone decreases food intake in obese humans. J. Clin. Endocrinol. Metab. 55:196-198; 1982.

7. Atkinson, R. L.; Berke, L. K.; Drake, C. R.; Bibbs, M. L.; Williams, F. L.; Kaiser, D. L. Effects of long-term therapy with naltrexone on body weight in obesity. Clin. Pharmacol. Ther. 38: 419-422; 1985 .

8. Bertiere, M. C.; Sy, T. M.; Baigts, F.; Mandenoff, A.; Apfelbaum, $M$. Stress and sucrose hyperphagia: Role of endogenous opiates. Pharmacol. Biochem. Behav. 20:675-679; 1984.

9. Blass, E. M. Opioids, sweets and a mechanism for positive affect: Broad motivational implications. In: Dobbing, J., ed. Sweetness. New York: Springer-Verlag; 1987:115-126.

10. Blass, E.; Fitzgerald, E.; Kehoe, P. Interactions between sucrose, pain and isolation distress. Pharmacol. Biochem. Behav. 26:483489; 1987.

11. Brown, D. R.; Holtzman, S. G. Suppression of deprivation-induced food and water intake in rats by naloxone. Pharmacol. Biochem. Behav. 11:567-573; 1979.

12. Calcagnetti, D. J.; Reid, L. D. Morphine and acceptability of putative reinforcers. Pharmacol. Biochem. Behav. 18:567-569; 1983.

13. Cohen, M. R.; Cohen, R. M.; Pickar, D.; Murphy, D. L. Naloxone reduces food intake in humans. Psychosom. Med. 47:132-138; 1985.

14. Cooper, S. J. Naloxone: Effects on food and water consumption in the non-deprived and deprived rat. Psychopharmacology (Berlin) $71: 1-6 ; 1980$

15. Cooper, S. J.; Jackson, A.; Kirkham, T. C.; Turkish, S. Endorphins, opiates and food intake. In: Rodgers, R. J.; Cooper, S. J., eds. Endorphins, opiates and behavioral processes. New York: Wiley and Sons; 1988:143-186.

16. Drewnowski, A. Taste responsiveness in eating disorders. In: Schneider, L. H.; Cooper, S. J.; Halmi, K. A., eds. The psychobiology of human eating disorders. Ann. NY Acad. Sci. 575:399-409 1990.

17. Drewnowski, A. Changes in mood following carbohydrate consumption. Am. J. Clin. Nutr. 46:703; 1987.

18. Drewnowski, A.; Brunzell, J. D.; Sande, K.; Iverius, P. H.; Greenwood, M. R. C. Sweet tooth reconsidered: Taste preferences in human obesity. Physiol. Behav. 35:617-622; 1985.

19. Drewnowski, A.; Bellisle, F.; Aimez, P.; Remy, B. Taste and bulimia. Physiol. Behav. 41:621-626; 1987.

20. Drewnowski, A.; Greenwood, M. R. C. Cream and sugar: Human preferences for high-fat foods. Physiol. Behav. 30:629-633; 1983.

21. Drewnowski, A.; Halmi, K. A.; Pierce, B.; Gibbs, J.; Smith, G. P. Taste and eating disorders. Am. J. Clin. Nutr. 46:442-450; 1987.

22. Drewnowski, A.; Kurth, C. L.; Rahaim, J. Taste preferences in human obesity: Environmental and familial factors. Am. J. Clin. Nutr. $54: 635-641 ; 1991$

23. Drewnowski, A.; Pierce, B.; Halmi, K. A. Fat aversion in eating disorders. Appetite 10:119-131; 1988.

24. Drewnowski, A.; Shrager, E. E.; Lipsky, C.; Greenwood, M. R. C.; Stellar, E. Sugar and fat: Sensory and hedonic evaluations of liquid and solid foods. Physiol. Behav. 45:177-183; 1989.

25. Dum, J.; Gramsch, C.; Herz, A. Activation of hypothalamic betaendorphin pools by reward induced by highly palatable fond. Pharmacol. Biochem. Behav. 18:443-447; 1983.

26. Fantino, M.; Hosotte, J.; Apfelbaum, M. An opioid antagonist naltrexone, reduces preference for sucrose in humans. Am. J. Physiol. 251:R91-R96; 1986

27. Fernstrom, M. H.; Kupfer, D. J. Imipramine treatment and preferences for sweets. Appetite 10:149-155; 1988.

28. Fullerton, D. T.; Getto, C. J. Sugar, opioids and binge-eating. Brain Res. Bull. 14:673-680; 1985

29. Getto, C. J.; Fullerton, D. T.; Carlson, I. H. Plasma immunoreactive beta-endorphin response to glucose ingestion in human obesity. Appetite 5:329-335; 1984

30. Givens, J. R.; Wiedemann, E.; Andersen, R. N.; Kitabchi, A. E. B-Endorphin and B-lipotropin plasma levels in hirsute women: Correlation with body weight. J. Clin. Endocrinol. Metab. 50:975-976; 1980.

31. Gosnell, B. A. Central structures involved in opioid-induced feeding. Fed. Proc. 46:163-167: 1987. 
32. Gosnell, B. A.; Krahn, D. D.; Majchrzak, M. J. The effects of morphine on diet selection are dependent upon baseline diet preferences. Pharmacol. Biochem. Behav. 37:207-212; 1990.

33. Gosnell, B. A.; Levine, A. S.; Morley, J. E. The stimulation of food intake by selective agonists of mu, kappa and delta opioid receptors. Life Sci. 38:1081-1088; 1985.

34. Gosnell, B. A.; Majchrzak, M. J. Centrally administered opioid peptides stimulate saccharin intake in nondeprived rats. Pharmacol Biochem. Behav. 33:805-810; 1989.

35. Holtzman, S. G. Behavioral effects of separate and combined administration of naloxone and d-amphetamine. J. Pharmacol. Exp. Ther. 189:51-60; 1974.

36. Holtzman, S. G. Effects of narcotic antagonists on fluid intake in the rat. Life Sci. 16:1465-1470; 1975.

37. Holtzman, S. G. Suppression of appetitive behavior by naloxone: Lack of effect of prior morphine dependence. Life Sci. 24:219-226; 1979.

38. Jackson, H. C.; Sewell, R. D. E. Are delta-receptors involved in the regulation of food and water intake? Neuropharmacology 24: 885-888; 1985 .

39. Johnson, C. Initial consultation of patients with bulimia and anorexia nervosa. In: Garner, D. E.; Garfinkel, P. E., eds. Handbook of psychotherapy for anorexia nervosa and bulimia. New York: Guilford Press; 1985:19-51.

40. Kaye, W. H.; Pickar, D.; Naber, D.; Ebert, M. H. Cerebrospinal fluid opioid activity in anorexia nervosa. Arch. Gen. Psychiatry 41: $350-355 ; 1984$

41. Kirkham, T. C.; Cooper, S. J. Attenuation of sham feeding by naloxone is stereospecific: Evidence for opioid mediation of orosensory reward. Physiol. Behav. 43:845-847; 1988.

42. LeMagnen, J. A role for opiates in food reward and food addiction, In: Capaldi, E. D.; Powley, T. L., eds. Taste, experience and feeding. Washington, DC: APA Press; 1990:241-252.

43. Levine, A. S.; Grace, M.; Billington, C. J.; Portoghese, P. S. Norbinaltorphamine decreases deprivation and opioid-induced feeding. Brain Res. 534:60-64; 1990

44. Levine, A. S.; Morley, J. E. Butorphanol tartrate induces feeding in rats. Life Sci. 32:781-785; 1983.

45. Lynch, W. C.; Libby, L. Naloxone suppresses intake of highly preferred saccharin solutions in food deprived and sated rats. Life Sci. 33 ; 1909-1914; 1983.

46. Maggio, C. A.; Presta, E.; Bracco, E. F.; Vasselli, J. R.; Kissileff, H. R.; Pfohl, D. N.; Hashim, S. A. Naltrexone and human eating behavior: A dose-ranging inpatient trial in moderately obese men. Brain Res. Bull. 14:657-664; 1985.

47. Mandenoff, A.; Fumeron, F.; Apfelbaum, M.; Margules, D. L. Endogenous opiates and energy balance. Science 215:1536-1538; 1982.

48. Margules, D. L.; Moisset, B.; Lewis, M. J.; Shibuya, H.; Pert, C. B. Beta-endorphin is associated with overeating in genetically obese mice $(\mathrm{ob} / \mathrm{ob})$ and rats $(\mathrm{fa} / \mathrm{fa})$. Science $202: 988-991 ; 1978$.

49. Marks-Kaufman, R.; Kanarek, R. Modifications of nutrient selection induced by naloxone in rats. Psychopharmacology (Berlin) 74 321-324; 1981

50. Marks-Kaufman, R.; Kanarek, R. B. Morphine selectively influences macronutrient intake in the rat. Pharmacol. Biochem. Behav. $12: 427-430 ; 1980$.

51. Mitchell, J. E.; Hatsukami, D.; Eckert, E.; Pyle, R. L. Characteristics of 275 patients with bulimia. Am. J. Psychiatry 142:482-485; 1985.

52. Mitchell, J. E.; Laine, D. E.; Morley, J. E.; Levine, A. S. Naloxone but not CCK-8 may attenuate binge-eating behavior in patients with the bulimia syndrome. Biol. Psychiatry 21:1399-1406; 1986.

53. Mitchell, J. E.; Morley, J. E.; Levine, A. S.; Hatsukami, D.; Gannon, M.; Pfohl, D. High-dose naltrexone therapy and dietary counseling for obesity. Biol. Psychiatry 22:35-42; 1987.

54. Morabia, A.; Fabre, J.; Chee, E.; Zeger, S.; Orsat, E.; Robert, A.
Diet and opiate addiction: A quantitative assessment of the diet of non-institutionalized opiate addicts. Br. J. Addict. 84:173-180; 1989.

55. Morley, J. E.; Levine, A. S. Stress induced eating is mediated through endogenous opiates. Science 209:1259-1261; 1980.

56. Morley, J. E.; Levine, A. S. Involvement of dynorphin and the kappa opioid receptor in feeding. Peptides 4:797-800; 1983.

57. Morley, J. E.; Levine, A. S.; Grace, M.; Kniep, J. An investigation of the role of kappa opiate receptor agonists in the initiation of feeding. Life Sci. 31:2617-2626; 1982.

58. Morley, J. E.; Levine, A. S. The role of the endogenous opiates as regulators of appetite. Am. J. Clin. Nutr. 35:757-761; 1982

59. Morley, J. E.; Parker, S.; Levine, A. S. Effect of butorphanol tartrate on food and water consumption in humans. Am. J. Clin. Nutr. 42:1175-1178; 1985 .

60. Moskowitz, H. R. Taste and food technology: Acceptability, aesthetics and preference. In: Carterette, E. C.; Friedman, M. P., eds. Handbook of perception v. VIA. New York: Academic Press; 1978 157-194.

61. Paykel, E. S.; Mueller, P. S.; De la Vergne, P. M. Amitryptiline, weight gain, and carbohydrate craving: A side effect. Br. J. Psychiatry $123: 501-507 ; 1973$.

62. Pennington, J. A. T.; Church, H. N. Food values of portions commonly used. New York: Harper and Row; 1980.

63. Reid, L. D. Endogenous opioid peptides and regulation of drinking and feeding. Am. J. Clin. Nutr. 42:1099-1132; 1985.

64. Romsos, D. R.; Gosnell, B. A.; Morley, J. E.; Levine, A. S. Effects of kappa opiate agonists, cholecystokinin and bombesin on intake of diets varying in carbohydrate-to-fat ratio in rats. J. Nutr 117:976-985; 1987.

65. Rosenthal, N. E.; Genhart, M.; Jacobsen, F. M.; Skwerer, R. G.; Wehr, T. A. Disturbances of appetite and weight regulation in seasonal affective disorder. Ann. NY Acad. Sci. 499:216-230; 1988.

66. Sanger, D. J.; McCarthy, P. S. Differential effects of morphine on food and water intake in food deprived and freely-feeding rats. Psychopharmacology (Berlin) 72:103-106; 1980.

67. Shide, D. J.; Blass, E. M. Opioid-like effects of intraoral infusions of corn oil and polycose on stress reactions in 10-day-old rats. Behav. Neurosci. 103:1168-1175; 1989

68. Spiegel, T. A.; Stunkard, A. J.; Shrager, E. E.; O'Brien, C. P.; Morrison, M. F.; Stellar, E. Effect of naltrexone on food intake, hunger and satiety in obese men. Physiol. Behav. 40:135-141; 1987.

69. Tomelleri, R.; Grunewald, K. K. Menstrual cycle and food crav. ings in young college women. J. Am. Diet. Assoc. 87:311-316; 1987.

70. Trenchard, E.; Silverstone, T. Naloxone reduces the food intake of normal human volunteers. Appetite 4:43-50; 1982 .

71. Tuschl, R. J. From dietary restraint to binge eating: Some theoretical considerations. Appetite 14:105-109; 1990.

72. Willenbring, M. L.; Morley, J. E.; Krahn, D. D.; Carlson, G. A.; Levine, A. S.; Shafer, R. B. Psychoneuroendocrine effects of methadone maintenance. Psychoneuroendocrinology 14:371-391; 1989.

73. Wolkowitz, O. M.; Doran, A. R.; Cohen, M. R.; Cohen, R. M.; Wise, T. N.; Pickar, D. Single-dose naloxone acutely reduces eating in obese humans: Behavioral and biochemical effects. Biol. Psychiatry 24:483-487; 1988.

74. Wurtman, J. J. The involvement of brain serotonin in excessive carbohydrate snacking by obese carbohydrate cravers. J. Am. Diet. Assoc. 9:1004-1007; 1984

75. Yeomans, M. R.; Wright, P.; Macleod, H. A.; Critchley, J. A. J. $H$. Effects of nalmefene on feeding in humans. Psychopharmacology (Berlin) 100:426-432; 1990.

76. Yirmiya, R.; Lieblich, I.; Liebeskind, J. C. Reduced saccharin preference in CXBK (opioid receptor-deficient) mice. Brain Res. 438:339-342; 1988. 